\title{
Mobile Health Applications and Human Papillomavirus: Raising Awareness in the Twenty-Tens
}

 \\ Siafaka $^{3}$
}

${ }^{1}$ Department of Obstetrics and Gynecology, University Hospitals of Birmingham, UK

${ }^{2}$ Department of Obstetrics and Gynecology, University Hospital of Ioannina, Greece

${ }^{3}$ Health Psychology, Department of Speech and Language, University of Ioannina, Greece

Submission: May 18, 2020; Published: June 03, 2020

*Corresponding author: Orestis Tsonis, Senior Registrar in Obstetrics and Gynecology, University Hospital of Ioannina Stavrou Niarchou Avenue, 45500, Ioannina, Greece

\section{Data Sharing Policy}

The data that support the findings of this study are openly available on the internet. Data retrieved by the official software market sites of Apple iTunes, Android Google Play, Blackberry World and Windows Phone Store. Precis

A research on the available mobile Health applications addressing HPV with a focus on the applications features such as vaccination planner, evidence-based medicine, medical health involvement.

\section{Abstract}

Objectives: Nowadays smartphones are taking over our life making them indispensable tools not only for fun and games but also when it comes to medical issues. Mobile Health applications (mHealth apps) are addressing various medical condition, giving essential information to patients and medical stuff, as well as, promoting health awareness.

Methods: For this study, mHealth apps were collected by four major app markets (Apple iTunes, Android Google Play, Blackberry World and Windows Phone Store), only because they are the most popular. Keywords were used in regard to HPV, HPV prevention, HPV vaccine and vaccination, Pap test, Pap smear

Results: Twenty-one (21) mHealth apps addressing HPV were found. Each app was assessed based on: Target Consumer, App's cost, Documentation of Evidence based practice, Documentation of Medical Professional Involvement, App rates, App reviews, Vaccination planner, Self-assessment tool, Multimedia used, Information on the subject, Educational tool, Social Networking and HPV test results clarification

Conclusion: In this study we tried to identify mHealth apps focusing on Human Papillomavirus (HPV) in different mobile software markets. Undeniably, this software can, potentially, play an important role in the prevention of the disease by providing information, promoting vaccination, and raising awareness.

Keywords: HPV; mHealth apps; HPV vaccination; HPV awareness

\section{Introduction}

Smartphone-mobile apps are highly popular in our everyday life. There can be used as educational tools and social networking or for entertainment. In medical field, a special marketplace has been raised giving birth to mobile Health apps [1]. Mobile Health's apps focusing on specialized medical condition and can provide to the user much different information; can be used as educational tool or more rarely as a diagnostic tool. According to literature there is at least one app for every medical condition [2]. For certain, careful design of these mHealth apps must be achieved, 
so that information sharing is accurate and up to date [3]. Female users seem to be more frequent users of the medical apps [4]. As result, many mHealth apps focus on woman's health, on the improvement of the quality of life and on a better understanding of certain diseases (HPV, endometriosis, menstrual cycle, gestation calculation, menopause etc.) [4,5]. There are many examples of mHealth apps in a variety of medical subjects such as obesity, menstrual period, heart disease, urogynecology, pregnancy, endometriosis etc $[6,7]$. The development of the mHealth apps will potentially lead in converting the smartphones in useful medical tools, leading possibly to a better healthcare system worldwide [8].

There are many software markets for mHealth apps such as Apple iTunes, Android Google Play, Blackberry World and Windows Phone Stores, to name a few-widely used. HPV considers to be the cause for cervical cancer [9]. A huge number of women die each year due to this HPV related cancer [10]. The first vaccine against the virus was introduced in 2006. Nevertheless, adoption of the vaccination is relatively slow and medical professionals ought to raise awareness. Especially in women 20-24 years of age, where HPV infection found to have the highest prevalence $(44,8 \%)$ in the US [11]. This age group is well adjusted to the mobile communications concept. For this reason, mHealth apps specified in HPV prevention should be promoted [12]. The aim of this study is to identify all mHealth apps regarding HPV prevention, including vaccination planners, educational tools, as well as, HPV test results comprehension. These mHealth apps will also be assessed for the extent of Evidence Base (EB) documentation and the Medical Professional Involvement (MPI). Last but not least, this study will focus on the lifestyle tips women should adopt in order to prevent the HPV infection, as well as, its use as a valid HPV screening reminder.

\section{Methods}

For this study, mHealth apps were collected by four major app markets (Apple iTunes, Android Google Play, Blackberry World and Windows Phone Store), only because they are the most popular8. Keywords were used in regard to HPV, HPV prevention, HPV vaccine and vaccination, Pap test, Pap smear.

Our team tried to extract data from all 4 app stores, targeting on:
a. Target Consumer
b. App's cost
c. Documentation of Evidence based practice
d. Documentation of Medical Professional Involvement
e. App rates
f. App reviews
g. Vaccination planner
h. Self-assessment tool
i. Multimedia used
j. Information on the subject
k. Educational tool
l. Social Networking
m. HPV test results clarification

A number of mHealth apps regarding a variety of Sexually Transmitted Diseases was noted (Herpes simplex, HIV etc.). The mHealth apps not relating strictly with HPV prevention were excluded. Non-English mHealth apps were also excluded (Figure 1).






\section{Results}

In this study, 21 mHealth apps were identified, from which 3 were excluded as they were referring to specific courses and congresses, in which only members had access. Five more were excluded since they were identified as duplicates, available for downloading by more than 1 app stores. Finally, thirteen mHealth apps regarding HPV were included for this study (Table 1, Table 2). The first release of a mHealth app regarding HPV was in 2012, while the majority of these apps were released after 2016. The search included data from 2012 till April 2020.

Table 1: HPV mHealth apps' features.

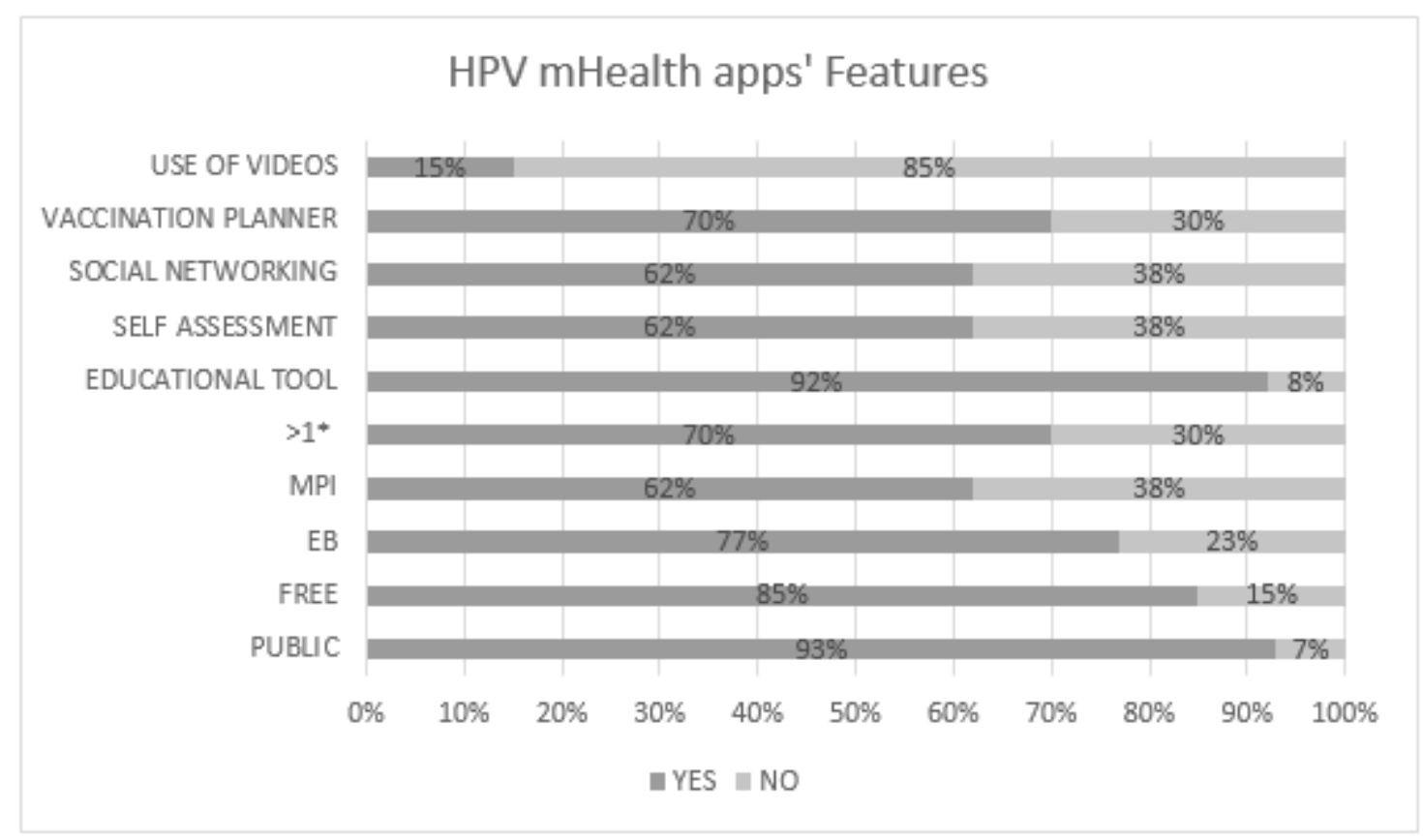

Table 2: Breakdown of HPV mHealth apps.

\begin{tabular}{|c|c|c|c|c|c|c|c|}
\hline Apps Name & Target Consumer & COST & MEDIAN COST & EB & MPI & $\begin{array}{c}\text { Rating (stars) } \\
\mathbf{0}-\mathbf{5}\end{array}$ & Function \\
\hline HPV vaccine & Public & FREE & N/A & YES & YES & 4 & $\begin{array}{c}\text { EDUC. TOOL SELF ASSESS } \\
\text { VACCINATION PLANER }\end{array}$ \\
\hline Fight HPV & $\begin{array}{c}\text { Medical Professionals \& } \\
\text { Public }\end{array}$ & FREE & N/A & YES & YES & 5 & EDUC. TOOL \\
\hline PAP TEST & Public & FREE & N/A & YES & YES & - & EDUC. TOOL \\
\hline PAP READER & $\begin{array}{c}\text { Medical Professionals \& } \\
\text { Public }\end{array}$ & FREE & N/A & YES & YES & 5 & EDUC. TOOL SELF ASSESS \\
VACCINATIONPLANER
\end{tabular}




\begin{tabular}{|c|c|c|c|c|c|c|c|}
\hline E-HPV & Public & FREE & $\mathrm{N} / \mathrm{A}$ & YES & YES & 4 & $\begin{array}{l}\text { EDUC.TOOL SELF ASSESS VACCINA- } \\
\text { TION PLANER }\end{array}$ \\
\hline HPV INFO & Public & FREE & $\mathrm{N} / \mathrm{A}$ & NO & NO & - & EDUC. TOOL \\
\hline STOP HPV & Public & FREE & N/A & NO & NO & 4 & $\begin{array}{l}\text { EDUC.TOOL SELF ASSESS } \\
\text { VACCINATION PLANER }\end{array}$ \\
\hline Plan HPV & Public & FREE & $\mathrm{N} / \mathrm{A}$ & YES & YES & 5 & $\begin{array}{l}\text { EDUC.TOOL SELF ASSESS } \\
\text { VACCINATION PLANER }\end{array}$ \\
\hline Genital Warts & Public & FREE & $\mathrm{N} / \mathrm{A}$ & NO & NO & 1 & EDUC. TOOL \\
\hline Let's ПАП & Public & FREE & $\mathrm{N} / \mathrm{A}$ & YES & YES & 5 & $\begin{array}{l}\text { EDUC.TOOL SELF ASSESS } \\
\text { VACCINATION PLANER }\end{array}$ \\
\hline $\begin{array}{l}\text { GLOBAL PAP } \\
\text { APP }\end{array}$ & Public & FREE & N/A & YES & YES & 3 & EDUC. TOOL \\
\hline
\end{tabular}

\section{Language set up}

Likely more than $54 \%$ (7 out of $13 \%$ ) of the mHealth HPV apps used in English, is having the option of more languages. This interesting feature is showing the worldwide tendency in HPV awareness, surpassing the limit of countries boundaries.

\section{Consumer target}

Almost 70\% (9 out of 13) of the mHealth HPV apps are aiming commercially the public, but only 1 out of 13 is designed as tool for both public and medical staff.

\section{Cost of mHealth HPV app}

Only 2 out of 13 (almost 15\%) have a charge of a median 5.5 pounds. The remaining mHealth HPV apps are available for download for free.

\section{Evidence Based and Medical Professional Involvement in development}

Nowadays, it is known that the cause of cervical cancer is the HPV infection. Even though, it seems that women need more evidence in order to understand and this condition and the risks. Women seem to look for more information about the vaccine and its use. Fortunately, 76.9\% (10 out of 13) of these mHealth HPV apps have evidence base information, whereas medical professional involvement was noted in $61.5 \%$ (8 out of 13). Luckily, 92\% (12 out of 13) of the mHealth apps could be used as educational tools for public, medical staff or even both.

\section{Ratings}

In these app stores the user has the option of rating with the star system. That means that one star is the worse grade and 5 stars is the best rate, when the app meets all expectations. In 76.9\% (10 out of 13) mHealth apps, which were rated, the medium rate was 4,1 showing how well this mHealth apps were received. The user had also the option of commenting. The median comments were 5 , were in 1 case of a Greek original mHealth HPV app, 75 comments were noted! In the majority of cases, comments of few words were referring to the user's opinion in regard to her experience with the app.

\section{Self-assessment - Vaccination planner}

More than half of the mHealth HPV apps in this study were based on self-assessment experience. Almost 70\% (8 out of 13) could remind the user of vaccination appointments according to medical guidelines. This feature gave the user the option to schedule a calendar notification in a timely manner prior to the due date of vaccination.

\section{Multimedia use}

In our study, we were able to note apps which are using pictures or videos, in order to achieve a better understanding from the users. In $38.4 \%$ (5 out of 13) of the mHealth apps explanatory pictures were attached, and almost 15\% (2 out of 13) involved videos 


\section{Social Networking and Family Sharing}

In the majority of the mHealth HPV apps studied, there was a feature for family sharing information and simultaneously sending information to different social media (Facebook, Twitter). Nevertheless, the app guide could not provide enough information about the level of protection of private information between family members.

\section{Educational Tool}

In all 13 mHealth apps, essential information about HPV was given and $92 \%$ (12 out of 13) of the apps could be used as educational tool from both public and medical staff. In less than half of them, the app could explain the result of an HPV test to the user. This information could help users better understand the disease, and also offer prevention strategies such as the importance of vaccination and sexual attitudes that ought to be followed in terms of eliminating the chance of infection by this virus.

\section{Discussion}

Different and exciting innovations in mHealth and social media applications are occurring from primary prevention, screening, early diagnosis, and treatment. These new platforms and technologies require the social engagement and support. These tools can become personalized data points for patients and help providers to deliver bespoke, more efficient care [13]. If we consider these apps addressing the HPV as tools, capable of educating public and by extent preventing cancer, it is even more important to provide good quality and up-to-date mobile apps. These are screening apps, which can raise awareness, and links to patient communities or providers for symptom management. Advantages of social media and mHealth technologies include low or no cost, high scalability, self-tracking, and tailored feedback functionalities, use of images and video for enhanced health literacy, broad reach, and data sharing for large-scale analytics. When it comes to HPV or any other sexually transmitted disease in general, the social stigma can be avoided by a simple click. People can potentially get educated, without the need to attend special clinics or having face to face consultations. People need to get more educated on matters like that. Campaigns supporting the mHealth use should be expanded so that worldwide prevention of certain avoidable diseases can be established.

There is a lack of Evidence Base medicine as well as a medical professional involvement in the mHealth apps. It is important to raise concerns about these apps' safety. In addition, the medical society has to establish clear rules and conditions according which the mHealth apps have to be developed. It is necessary also to secure the data collected and the confidentiality. It is important to mention that in our study, we were not able to locate an app related to the HPV in two of the marketplaces used. Hopefully, it is a matter of time that these apps could raise awareness for HPV prevention and could even facilitate users-patients stay in tract with their vaccination status. Although development efforts have been rapid and numerous, frameworks and investigations of efficacy for achieving and sustaining behavioral change and positive health outcomes are needed. Tailored apps also needed, in order to address the same problem to people with different ethnicity or mentality. Further investment in research, will help to identify best practices and as consequence to delineate and actualize the potential of social media and mHealth technologies for cancer prevention and treatment [14].

This overview raises several research questions around apps and their quality, of which the following seem important to investigate soon

a. What are the quality criteria with which healthcare professional and patients choose health apps?

b. What are the apps features that provide acceptability and accuracy?

c. What is the benefit of designing an app which supports the self-management of a medical condition?

d. How the user's features such as the age and gender affect the engagement and effectiveness of apps use?

Answering these questions should help apps to be developed smoothly and safely, be improved constantly, and deliver their great potential. It is obvious that there is a need of developing more apps, safer and more accurate. The involvement of medical and para-medical staff is always welcomed to mandatory, in order to keep their context up-to-date and according to the evidencebased best practice.

\section{References}

1. Slomian J, Reginster JY, Ethgen 0 , Appelboom G, Bruyère 0 (2014) Opportunity and Challenges of eHealth and mHealth for Patients and Caregivers. Aust J Public Health Epidemiol 1(2): 1009.

2. Wac K (2012) Smartphone as a personal, pervasive health informatics services platform: literature review. Yearbook of medical informatics 21(01): 83-93.

3. Sherlaw W (2016) Ethical issues in using and assessing m-health within health promotion William Sherlaw. European Journal of Public Health 26(1).

4. Action O (2014) women taking the lead when It comes to Mobile.

5. Rotheram Borus MJ, Tomlinson M, Swendeman D, Lee A, Jones E (2012) Standardized functions for smartphone applications: examples from maternal and child health. International journal of telemedicine and applications 2012: 21.

6. Derbyshire E, Dancey D (2013) Smartphone medical applications for women's health: What is the evidence-base and feedback? International journal of telemedicine and applications 2013: 9.

7. Arbour MW, Stec MA (2018) Mobile Applications for Women's Health and Midwifery Care: A Pocket Reference for the $21^{\text {st }}$ Century. Journal of midwifery \& women's health 63(3): 330-334.

8. Mertz L (2012) Ultrasound? Fetal monitoring? Spectrometer? There's an app for that: biomedical smart phone apps are taking healthcare by storm. IEEE pulse 3(2): 16-21. 
9. Walboomers JM, Jacobs MV, Manos MM, F Xavier Bosch, J Alain Kummer et al. (1999) Human papillomavirus is a necessary cause of invasive cervical cancer worldwide. The Journal of pathology 189(1): 12-19.

10. Yoda LU, Nahl D (2013) Crosby ME Stage-based mHealth communication interventions for HPV education. System Sciences (HICSS), 2013 46th Hawaii International Conference on IEEE 2715-2724.

11. Dunne EF, Unger ER, Sternberg M, et al. (2007) Prevalence of HPV infection among females in the United States. Jama 297(8): 813-819.

12. Sherry JM, Ratzan SC (2012) Measurement and evaluation outcomes for mHealth communication: don't we have an app for that? Taylor \& Francis.
13. Kyrgiou M, Pouliakis A, Panayiotides J, Niki Margari, Panagiotis Bountris, et al. (2016) undefined. Personalised management of women with cervical abnormalities using a clinical decision support scoring system 141(1): 29-35

14. Murfin M (2013) Know your apps: an evidence-based approach to evaluation of mobile clinical applications. J Physician Assist Educ 24(3): $38-40$

\section{Your next submission with Juniper Publishers} will reach you the below assets

- Quality Editorial service

- Swift Peer Review

- Reprints availability

- E-prints Service

- Manuscript Podcast for convenient understanding

- Global attainment for your research

- Manuscript accessibility in different formats

( Pdf, E-pub, Full Tsext, Audio)

- Unceasing customer service

Track the below URL for one-step submission

https://juniperpublishers.com/online-submission.php 